\title{
12 Feeding Ecology of Piscivorous Fishes
}

\author{
FRANCIS JUANES, JEFFREY A. BUCKEL AND \\ FREDERICK S. SCHARF
}

\subsection{INTRODUCTION}

Fish exhibit tremendous diversity in feeding habits and the morphologies associated with feeding. A recent book (Gerking 1994) and various other overviews of fish feeding exist (Wootton 1990; Hobson 1991; Hart 1993). However, most of these tend to be general reviews of theory or focus on smaller non-piscivorous fishes. Our intent here is to review the feeding ecology of piscivorous fish, a subject which to our knowledge has never previously been reviewed. We focus on teleost fish, and on species and sizes that consume juvenile and adult prey and do not consider those that feed primarily on larvae or fish eggs.

\subsubsection{Why piscivorous fish?}

Piscivorous fish are broadly distributed phylogenetically and geographically, occur in most habitats and generally occupy the top of most aquatic trophic webs. Piscivorous fish also generally achieve the largest body size within fish communities, are represented by some of the largest species (many elasmobranchs, tunas, billfishes) and have potentially large impacts on their communities through predation. Finally, many piscivorous fishes, because of their ubiquity and large body size are among the most valuable harvestable species in many of the world's fisheries. In some cases, they compete with humans for commercially important resource species (V. Christensen 1996; Buckel et al. 1999a). Piscivorous fish as a group, however, are difficult to categorize and describe, which perhaps explains why no reviews of their ecology exist.

\subsection{ADAPTATIONS FOR PISCIVORY}

\subsubsection{What is a piscivore?}

We define piscivorous fish as carnivorous fish that consume primarily fish prey. Most fish species are opportunistic and flexible in their feeding habits (Dill 1983) and no species consumes only fish prey; however many do ingest fish as the main prey item. Fish that eat other fish are second in proportion to those feeding on benthic invertebrates and are present in a variety of freshwater, estuarine and marine systems. They are equally common in tropical and temperate ecosystems. Keast (1985) examined the piscivore feeding guild of small lakes and streams and categorized piscivorous fish into primary and secondary piscivores. Primary or 'specialized' piscivores shift to piscivory within the first few months of life, whereas secondary piscivores only become fish-eaters later in life. Keast further suggests that secondary piscivores switch to fish as a way to maintain energetic efficiency as they grow. This can only be achieved by eating progressively larger prey and, at a certain point, fish are the only prey available. Furthermore, secondary piscivores are not structurally adapted for piscivory other than acquiring a large mouth as they age. 


\subsubsection{What are the adaptations for piscivory?}

Feeding behaviours and morphological adaptations

When observed in detail it becomes clear that piscivore feeding behaviour is complex and flexible in dealing with different prey types. Behaviours can generally be grouped into the following categories, which are also associated with particular morphological adaptations.

Luring Luring is a sit-and-wait behaviour where prey are attracted by a 'lure', which consists of a stalk topped by a device that resembles a source of food; the lure is a modification of the first dorsal spine (Gerking 1994). Luring is typical of the anglerfish (order Lophiiformes). In addition, among the frogfish various morphological features allow the predator to blend into the rocky environments in which they live as a form of camouflage. Anglerfish have a considerable gape and ingest prey sizes that are large compared to other piscivores.

Stalking Stalking is the unobtrusive pursuit of prey before the attack occurs. This strategy is common to trumpetfish (Aulostomidae), longnose gar (Lepisosteidae) and needlefish (Belonidae). These species have similar morphologies, long slender bodies with a long snout and sharp teeth.

Chasing Large piscivores are able to chase and 'swim-down' prey. This strategy is best represented by the billfish (Xiphiidae and Istiophoridae) and some tuna (Scombridae) and yellowtail orpompano (Carangidae). These fish must be able to attain high cruising and accelerating speeds. Their bodies can be described as thunniform or carangiform, where thrust is maximized by a lunate tail with a high aspect ratio, a narrow caudal peduncle that minimizes sideways thrust and a large anterior body depth that minimizes recoil of the head end. These same features, along with a relatively rigid and streamlined body, also minimize drag (see Brix, Chapter 4, this volumel. Chasers can be either lungers, such as the pike (Esox spp.), where attacks are started at close range from an S-shaped position, strikes occur at high speed and missed prey are rarely pursued, or they can be pursuers such as trout (Salmo trutta), where attacks start from a C-shaped position, strikes occur at low speeds from a short distance and missed prey are chased.

Ambush This strategy is used by species that attack from seclusion, although an element of chasing may also occur. Examples are morays (Muraenidae), pike (Esocidae) and summer flounder (Pleuronectidae). Few morphological similarities exist in species that use this behaviour other than the ability to use camouflage and high-speed attacks. However, distinct patterns of kinematic, pressure, electromyographic and behavioural profiles of prey capture are exhibited by ambushers and pursuers.

Other A variety of other rarer feeding habits each with their own specialized morphologies, particularly in the dentition, include forms of parasitism such as blood-sucking in lampreys (Petromyzontidae) and catfishes (Trichomycteridae and Cetopsidae), scale-eating in many cichlids and characoids, and fin and eye-biting (Gerking 1994).

A novel feeding behaviour common to planktivores has recently been observed for a few species of piscivores (Sazima 1998). Ram suspension (or filter) feeding is defined as swimming through the water with the mouth wide open and opercles flared as a way of filtering small prey items out of the water column without directing attacks towards individual prey. This may be a mechanism used by piscivores feeding on relatively small prey in high concentrations (B. Hanrahan and F. Juanes, personal observation).

Most piscivores ingest their prey whole. A few species are able to tear off and ingest pieces and good examples are piranhas (Serrasalmus spp.) and African tiger fish (Hydrocyon vittatus). The most detailed analysis of partial prey eating has been performed for bluefish (Pomatomus saltatrix) (Juanes and Conover 1994a; Scharf et al. 1997). Juvenile bluefish switch from taking prey whole to partial prey consumption when the prey to predator size ratio is about 0.35 independent of 
prey type (Scharf et al. 1997). This ability allows bluefish to attack much larger prey sizes than can predators of similar size and is likely to be a function of specialized musculature and dentition. Bluefish are also unique in that they ingest prey tail-first, whereas most other piscivores that have been examined eat prey head-first. Tail-first ingestion may be a result of pursuing prey rather than ambushing it, or a way to reduce prey mobility thereby increasing prey vulnerability, as has been observed in piranhas.

\section{Schooling in predators}

Schooling by prey is generally thought of as an adaptation for evading, confusing and reducing the efficiency of predators (Pitcher and Parrish 1993). Schooling also has hydrodynamic and foraging functions. Little empirical work has been done on whether schooling by predators enhances predation efficiency in piscivores. Field studies have shown that, in general, group attacks tend to result in higher capture success rates (Pitcher and Parrish 1993). Eklöv (1992) has shown that the foraging efficiency, measured as growth rate, varies between a group-foraging, actively searching piscivore (Eurasian perch, Perca fluviatilis) and a solitary-foraging, stalking piscivore (pike, Esox lucius). Under similar conditions, grouped perch grew more than single perch or grouped pike. In contrast, solitary pike grew better than solitary perch or grouped pike. Schooling in piscivores may have foraging costs and benefits. Prey encounter rates may be maximized but the probability of losing a prey item to kleptoparasitism is also greater when predators attack in groups (Juanes and Conover 1994a). There has been anecdotal information collected that suggests that some piscivorous fish hunt cooperatively (Pitcher and Parrish 19931, although potential mechanisms have not been quantified under controlled conditions.

Active piscivorous pelagic fishes are characterized by a range of length to maximum depth ratios (the fineness ratio), which ranges from 4.0 to 6.5 and which maximizes feeding efficiency and minimizes drag (Blake 1983). Bluefish, a primary piscivore that switches to fish prey at about $40 \mathrm{~mm}$ total length, has a fineness ratio between 3.5 and 5.0 (Juanes et al. 1994). Interestingly, offshore invertebrate-feeding juveniles $(<40 \mathrm{~mm})$ are already morphologically specialized for piscivory, suggesting a trade-off between feeding efficiency and future diet. A result of this trade-off may be to accelerate the onset of piscivory.

\section{Life history}

Onset of piscivory Most piscivorous fish undergo ontogenetic shifts in diet (Werner and Gilliam 1984; Keast 1985; Winemiller 1989). These shifts generally progress from consumption of zooplankton to consumption of benthic macrofauna or prey fish, with a concomitant increase in mean prey size as predators grow. There is much variation in the timing of the shift to piscivory among primary and secondary piscivores (Mittelbach and Persson 1998; Mittelbach, Chapter 11, this volume). A few species of scombrids apparently forgo the zooplanktivorous stage and start eating fishes at first feeding, whereas others shift early in the larval period (Tanaka et al. 1996). The shift to piscivory invariably results in an increase in predator growth rate (Buijse and Houthuijzen 1992; Juanes and Conover 1994b; Olson 1996). Among the scombrids studied by Tanaka et al. (1996), there was a direct correlation between the age at the onset of piscivory and early growth, with those species shifting to piscivory at first feeding capable of reaching $100 \mathrm{~mm}$ during the first month of life.

Within fish cohorts, the largest individuals are often able to switch to piscivory while the smallest are delayed and experience reduced growth. This effect leads to the often-observed bimodality in size distribution of juvenile piscivores (Adams and DeAngelis 1987; Frankiewicz et al. 1996). Because survivorship is generally size-selective in fish (Sogard 1997), bimodality can result in increased mortality of individuals in the smaller size mode (Olson 1996).

What allows species to shift to piscivory? The timing of the onset of piscivory depends on predator morphology, predator and prey phenologies, prey abundance and abiotic factors. Clearly predators 
have to be larger than their prey in order to be able to ingest them. Large body size and large mouth gapes are therefore generally considered an important constraint on prey use, particularly piscivory (Werner 1977; Wainwright and Richard 1995; Mittelbach and Persson 1998). Biomechanical features such as jaw mechanics and tooth development have also been implicated (Jenkins et al. 1984; Wainwright and Richard 1995). Among piscivorous scombrids, ontogenetic development of the digestive system (Tanaka et al. 1996) and development of the visual system (Margulies 1997) have been correlated with the onset of piscivory. Walleye (Stizostedion vitreum) generally shift to piscivory between 30 and $60 \mathrm{~mm}$ in length but are able to ingest larvae when they are as small as $10 \mathrm{~mm}$; the earlier onset of piscivory may be related to the abundance of prey in appropriate size ranges (Mathias and $\mathrm{Li}$ 1982). However, because the switch to piscivory is most often preceded by an invertebrate-feeding stage, piscivores must ensure rapid growth during that phase so that when fish prey are available the feeding shift can occur. If growth is slowed during the invertebrate-feeding stage, the piscivore size advantage over its fish prey is reduced leading to delays in the shift to piscivory (Olson 1996). Environmental factors such as low temperatures early in the growing season can also reduce growth and delay piscivory (Buijse and Houthuijzen 1992; Olson 1996).

Is acceleration of the onset of piscivory adaptive? Because of the dramatic increase in growth rate following the shift to piscivory and because sizeselective mortality is so prevalent among juvenile fishes (Sogard 1997), natural selection should favour life-history strategies in piscivores that minimize the length of the zooplanktivorous phase. One such strategy to attain an acceleration of the onset of piscivory would be to match the timing and location of spawning with the availability of fish prey. Freshwater primary piscivores have evolved the ability to spawn earlier than other fishes, thereby attaining sufficient size to allow them to consume juvenile fish spawned later in the same year. This pattern has been observed in largemouth bass (Micropterus salmoides), pike and walleye (Forney 1971; Keast 1985). Among marine fish it is much more difficult to examine the timing of predator and prey spawning. How ever, bluefish appear to have evolved a life-history strategy whereby they are spawned at approximately the same temperature as their future prey but at a more southern latitude. This divergence allows bluefish to attain the size advantage required when they shift to piscivory after being advected to higher latitude estuaries where their prey are abundant.

In a recent review of the freshwater fish literature, Mittelbach and Persson (1998) showed that those species born larger and with larger mouth gapes become piscivorous at younger ages and smaller sizes, although they did not find a relationship between spawning temperature, used as an indicator of timing, and size at the shift to piscivory or size at age 1 . However, species that accelerated the onset of piscivory by shifting early were larger at age 1 and continued to be larger through later ages.

A potential cost of early onset of piscivory is reduced growth and survival if habitat conditions dictate prey abundance. Furthermore, because most piscivores are strongly size-selective \{Juanes 1994\}, if availability of appropriately sized fish prey is delayed, growth may be reduced (Buckel et al. 1998).

\section{Resource polymorphisms}

Adaptive trophic specialization can in some cases lead to the evolution of resource polymorphisms, where trophically and morphologically specialized morphs can coexist and ultimately speciation can occur. Among fishes various examples of trophic polymorphisms include piscivorous morphs. For example, in Arctic charr (Salvelinus alpinus|, four trophic morphs are often recognized. The four morphs have differing life-history strategies, morphologies and behaviours that are genetically based (Skulason et al. 1993). Using life-history theory, Mangel (1996) has shown that the evolution of a large piscivorous morph in trout ('ferox' trout) can occur if the growth rates of the different asymptotic morph sizes differ and if 
there is size-dependent mortality. Other aspects of alternative life-history evolution caused by com. petitive reproductive behaviour are reviewed by Hutchings (Chapter 7 , this volume).

\subsection{COMPONENTS OF PREDATION}

\subsubsection{Search, encounter, pursuit, capture, handling}

For a prey fish to be included in the diet of a predator, it has to be located, pursued, captured, manipulated or handled, and finally digested (Mittelbach, Chapter 11, this volume). Each of these steps must be performed successfully by the predator in order for the predation process to be complete. Therefore, prey have several opportunities to avoid being eaten during the course of the interaction. The first of these is to not be detected. Predators have evolved various modes of searching for prey. At the same time, prey have evolved an assortment of behaviours to reduce their chances of being detected by potential predators (Krause et al., Chapter 13, this volumel. The probability of any one prey being encountered will then be determined by the morphological and behavioural characteristics of both predator and prey.

Most predators that consume motile prey, such as fish, utilize one of two basic search/encounter modes: ambush or sit-and-wait tactics and cruising tactics as described earlier. The types and sizes of prey eaten by a predator are often associated with the foraging tactics employed. For example, Greene (1986) showed that invertebrate predators that employed ambush tactics consumed larger prey relative to cruising predators. He further demonstrated that prey encounters for ambush predators were strongly dependent on prey swimming speeds, whereas variation in prey activity had no discernible effect on encounter rates for cruising predators. Among fish, ambush predators have also been shown to take larger prey relative to more actively searching predators. The inclusion of larger prey items in the diets of ambush predators is thought to be a function of their dependence on prey activity producing encounters and the positive relationship that exists between body size, prey movement and detectability.

The estimation of encounter rates between fish predators and prey remains an elusive problem in fish ecology. Specifically, for piscivorous fishes, the mobility of potential prey means that behaviours and movement patterns of both predator and prey will ultimately affect rates of encounter. Due to the variable nature of the plethora of environmental parameters that can influence the distribution of animals in space and time, encounter rates in situ are virtually impossible to measure with any certainty. Laboratory tanks used for piscivores and their prey are generally too small to yield any realistic estimates of encounter rate, as all prey are usually within the visual field of a given predator. Therefore, encounter probabilities are often estimated using mathematical models that incorporate average swimming velocities of predator and prey as well as a predator detection radius (Gerritsen and Strickler 1977). Although theoretical models can be quite elegant, they remain burdened with many assumptions that often cannot be tested. Because no predation can occur without an encounter first, much future research will be devoted to better understanding the factors that contribute to variable rates of encounter.

Once prey are encountered, predators must be sufficiently capable of capturing prey for it to be eaten. Piscivorous fishes generally have lower capture probabilities compared with planktivores. Usually about half of piscivore attacks on average are successful compared with $70-80 \%$ for planktivorous fishes. Capture success in piscivores has also been shown to be directly related to relative body sizes of prey and predator, and generally declines linearly as the prey size to predator size ratio increases (Fig. 12.1). Similar size-based capture success functions have been observed for several piscivore species representing different life stages (Miller et al. 1988; Juanes and Conover 1994a). Differences in prey type have also been shown to influence predator capture success, as prey escape proficiencies vary among species (Wahl and Stein 1988; Scharf et al. 1998). The strong dependence of piscivore capture success on prey size and type 


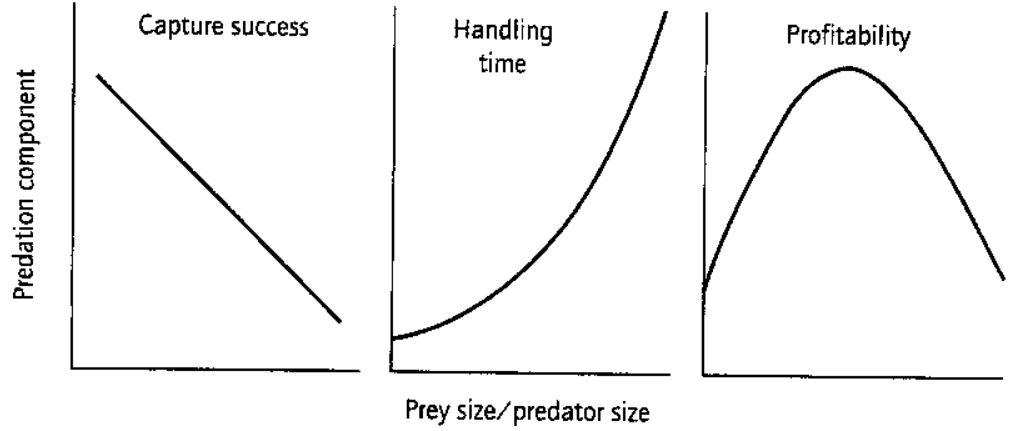

Fig. 12.1 General empirical relationships between predation components and relative prey size for piscivores. indicates that it plays an important role in determining relative vulnerabilities to predation for different prey.

Similar to capture success, handling time in piscivorous fishes is affected by both prey size and type. Because larger prey sizes often need to be manipulated before swallowing, increasing prey size typically causes an exponential increase in handling time (Fig. 12.1). The rate of increase in handling time has been shown to be unique for specific prey types (Hoyle and Keast 1987; Scharf et al. 1998). Handling time has historically been a critical parameter to estimate, as it has frequently been used to represent the primary energetic cost of feeding in theoretical foraging models attempting to predict predator diet (Mittelbach, Chapter 11, this volume). Although foraging models have demonstrated some success in predicting diets of planktivorous fishes, past models for piscivores have often failed (Sih and Christensen 2001). More recent models that incorporate differential capture probabilities based on prey size and type have proven more successful in predicting piscivore diets (Rice et al. 1993). The combination of sizedependent encounter rates, capture probabilities, energy content and handling times can be used to construct profitability functions for specific prey types. For piscivores, these functions are typically dome-shaped curves that peak at intermediate ratios of prey size to predator size (Fig. 12.1). However, most often encounter rates cannot be estimated with confidence and curves are constructed using only capture success and handling time functions. The specific relation, for each prey type, between encounter probability and prey size will determine whether the profitability peak is shifted toward smaller or larger relative prey sizes. Accurate profitability functions that incorporate a broad range of prey and predator sizes can be extremely valuable for predicting piscivore diets.

\subsubsection{Functional and numerical responses}

Predatory response to variations in prey density can be grouped into two categories. The functional response refers to the number of prey eaten per predator per unit time as a function of prey density. Changes in number of predators in response to variations in prey density describes the numerical response.

\section{Functional responses}

There are several different forms of functional response. A subset of these have been classified as the type I, II and III models (Holling 1965). The type I response occurs when the number of prey eaten per predator per unit time increases linearly with increasing prey density (Fig. 12.2a). The proportion of prey density consumed stays constant and this response is also called density-independent predation (Fig. 12.2d). Most vertebrates have a type II or III functional response (Hassell 1978). The type II response is represented by a negatively accelerating curve (Fig. 12.2b); therefore, the proportion of prey density consumed decreases with increasing 


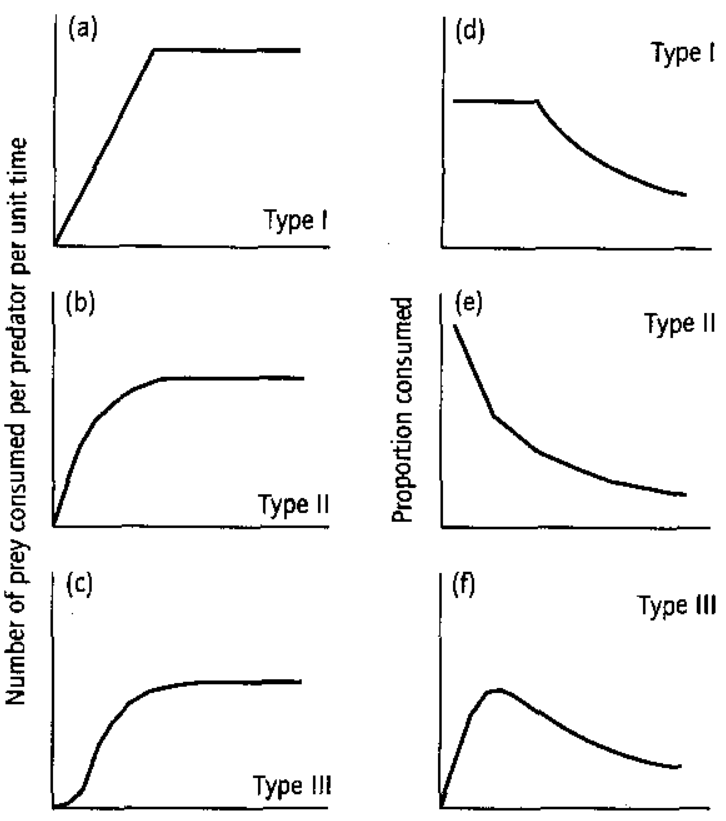

Number of prey present

Fig. 12.2 $|\mathrm{a}-\mathrm{c}|$ Shapes of hypothetical functional responses: $\{a \mid$ type I, (b) type II and (c) type III. (d-f) Proportion of prey consumed or percentage mortality corresponding to the functional responses: (d) type I, (e) type $\Pi$ and (f) type III.

prey density and is referred to as negative densitydependent predation. Under this regime the risk of being preyed upon is high at low prey densities but decreases with increasing prey density (Fig. 12.2e). Positive density-dependent predation can result when a predator feeds with a type III functional response. The shape of this function is sigmoidal (Fig. 12:2c); when the proportion of prey density consumed is plotted the slope is initially positive, meaning that the risk of being preyed upon is small at low prey densities but increases up to a certain point as prey density increases (Fig. 12.2f). Predation components such as attack rate and handling time \{Section 12.3.1\} can be estimated from these functions (Holling 1965; Hassell 1978).

In general, piscivorous fishes have a type II functional response. For example, type II responses were found in Arctic charr preying on migrating sockeye salmon (Oncorhynchus nerka) smolts
(Ruggerone and Rogers 1983) and southern flounder (Paralichthys lethostigma) preying on spot (Leiostomus xanthurus) (Wright et al. 1993). Lake trout (Salvelinus nemaycush) were capable of high predation rates at low prey fish densities, suggesting a type II response (Eby et al. 1995). Petersen and DeAngelis (1992) found that type II and III models gave similar fits to field data of northern squawfish (Ptychocheilus oregonensis) feeding on juvenile salmonids.

Although the type III functional response has not been observed with regularity, it has been proposed as a potential mechanism in regulating population abundance (see Section 12.6). Several factors can lead to a type III functional response, such as predator learning, prey refuge and the presence of alternative prey (Holling 1965). The presence and accessibility of a prey refuge has been hypothesized to be a factor leading to positive density-dependent mortality in some piscivore-prey systems (Bailey 1994; Hixon and Carr 1997). Alternative prey can lead to a type III functional response through switching behaviour (Murdoch and Oaten 1975). Prey switching occurs when the prey type with the highest relative abundance is included disproportionately more in the predator's diet than would be expected from random feeding (see Section 12.4.1 for an example).

Functional responses are critical parts of the multispecies virtual population analysis (MSVPA) method of modelling fish populations (Shepherd and Pope, Chapter 7, Volume 2). MSVPA differs from single-species virtual population analysis (SSVPA) in that interspecific and intraspecific predation are included to estimate levels of natural mortality, which in SSVPA is assumed constant. Generally, MSVPA has assumed a type II functional response, which may be reasonable for predators that do not depend on a small number of prey species, as in temperate systems, but may not be adequate for predators that do depend on few prey species, as in boreal systems. Inclusion of a type III response can have important effects on forecasts based on MSVPA, including producing more than one solution to MSVPA equations (Magnússon 1995; see also Shepherd and Pope, Chapter 7, Volume 2). 


\section{Numerical responses}

Predator numbers can respond rapidly to increasing prey density, as when predators aggregate on prey fish, or can respond slowly, such as increased reproductive success (Peterman and Gatto 1978). We know little about numerical responses in piscivorous fish. This is surprising given its potential importance in regulating population levels; the lack of data stems from the logistical difficulties of measuring such a response. Whenever a predator increases in density in response to increasing prey fish density, the total predation rate response can differ from the predator's functional response. A sigmoidal response (type III) may more typically describe a piscivore's total response; the total response is a function of both the functional and numerical response (Bailey 1994).

\subsection{PREY TYPE AND SIZE SELECTIVITY}

Selective predation can be defined as the consumption of prey in different proportions than those available in the predator's surrounding habitat (Chesson 1978; Mittelbach, Chapter 11, this volume). This is in contrast to random feeding, where predators feed indiscriminately on prey in accordance with their relative availability. Predators that feed in a random manner with respect to relative prey abundance levels are usually referred to as opportunistic feeders because they adjust their feeding habits rapidly to match variation in the local prey field. Predators that consume a narrow range of prey types or sizes regardless of changes in the prey field are thought of as specialists and represent the most extreme case of selective predation. Most predators fall somewhere along a continuum between opportunists and specialists.

\subsubsection{Observed patterns}

Numerous instances of prey type and size selection by piscivorous fishes have been reported in both freshwater and marine communities. For example, Wahl and Stein (1988) used laboratory experiments and large-scale field manipulations to determine patterns of prey selection in several freshwater predators, including muskellunge [Esox masquinongy), tiger muskellunge, and northern pike. Results demonstrated that each of the predators consistently selected for shad prey as opposed to Centrarchid prey. The authors concluded that behavioural and morphological differences between prey types resulted in differential vulnerability to predation and the observed patterns of selection. Research on the feeding habits of piscivorous bluefish in marine waters off the northern Atlantic coast of the USA have also revealed evidence for selective predation on specific prey types. Buckel et al. (1999b) demonstrated that, during early summer in shallow estuarine habitats, juvenile bluefish consumed young-ofthe-year striped bass (Morone saxatilis) in greater proportions than a random sampling of the prey environment, and that this positive selection was directly related to striped bass abundance. In other words, they showed prey switching behaviour as referred to in Section 12.3. During southerly autumn migrations in continental shelf waters, juvenile bluefish have also shown the propensity for selecting specific prey types, particularly bay anchovy (Anchoa mitchilli) (Buckel et al. 1999c). Selection for specific prey sizes may be even more prevalent than prey type selection among piscivorous fishes. A recent review of 32 laboratory and field studies concluded that selection for small prey from available size distributions was a common phenomenon for both freshwater and marine piscivores (Juanes 1994). This study also revealed that most piscivorous fishes consumed prey smaller than the optimal prey sizes predicted by energy maximization models, independent of both predator and prey type as well as predator size (Mittelbach, Chapter 11, this volume\}.

\subsubsection{Behavioural mechanisms of selective feeding}

Selective feeding can result from both morphological constraints of predators and behavioural interactions between piscivores and their prey. Predator gape size ultimately limits the sizes of prey in- 
gested and can also affect the types of prey consumed. However, recent studies indicate that behavioural capabilities of both predator and prey can regulate the sizes and types of prey eaten before morphological constraints become important. In a well-designed series of laboratory experiments, B. Christensen \{1996) evaluated the effects of prey antipredator behaviours on the sizes of roach (Rutilus rutilus) consumed by piscivorous Eurasian perch. Feeding experiments were conducted at two different spatial scales, determined by tank volumes, to control the level of antipredator behaviour expressed by the prey. In smaller arenas that limited prey escape ability, the author found that perch were able to consume large roach approaching gape limitations. In larger arenas, where prey antipredator behaviours were not suppressed, the maximum size of roach consumed by perch was significantly smaller. The author concluded that the sizes of prey eaten were largely dependent upon relative predator and prey mobility (Mittelbach, Chapter 11, this volume). Juanes (1994) hypothesized that common patterns of selection for small-sized prey by piscivorous fishes were the result of sizedependent vulnerabilities of prey to predator capture, rather than predator preferences. $\mathrm{He}$ proposed that many examples of selective feeding in fishes were actually passive selective processes rather than active predator choice, with attack rates being relatively equal among different prey sizes but smaller prey being consumed more frequently due to ease of capture (see also Hart and Hamrin 1990). Prey behaviour can also influence the rate of attack among different prey types available to a predator. For example, laboratory experiments demonstrated higher attack rates by goby (Gobiusculus flavescens) predators on herring (Clupea harengus) larvae compared with cod (Gadus morhua) larvae, with attack proportions being strongly related to differential levels of prey activity between the species (Utne-Palm 2000). Predictions of prey selection from most traditional foraging models assume that optimal choices are mainly the result of behavioural decisions by predators (Stephens and Krebs 1986). For piscivorous fish predators, the behavioural and foraging capabilities of both predator and prey can clearly alter attack and capture rates of predators and contribute significantly to the observed patterns of selective feeding.

\subsection{PREDATOR-SIZE AND PREY-SIZE RELATIONSHIPS}

Because they are the top predators in many aquatic systems, knowledge of the sizes of prey included in the diets of piscivorous fishes is essential in order to identify their potential impact on prey survival and their role in structuring populations at lower trophic levels. This is particularly important for the ecosystem approach to fisheries management, where knowledge of interactions is critical (Pauly and Christensen, Chapter 10, Volume 2). Further discussion of how size-dependent processes structure communities can be found in Persson, Chapter 15 , this volume. From a behavioural standpoint, relative body sizes of prey and predator can have significant effects on predator feeding success. Detection and capture of prey by piscivores are enhanced with increasing size for several reasons, including increased sustained and burst swimming speeds and better visual acuity (Webb 1976). The escapeproficiency of prey alsovaries with ontogeny as reaction distances increase and swimming abilities are improved with size (Brix, Chapter 4, this volume). Morphological characteristics that influence piscivore-prey interactions, such as predator gape size and robustness of prey morphological defences (e.g. spines), also scale with ontogeny. Therefore, identifying patterns of prey size use by piscivorous fishes can provide important clues as to the mechanisms that shape piscivore diets and the effects of predation by piscivorous fishes on community structure.

\subsubsection{Generalpatterns and hypotheses}

For piscivorous fishes, the sizes of prey consumed generally increase with predator size. In addition, the range of prey sizes eaten typically increases in larger predators, as maximum prey size often increases rapidly while minimum prey size may 


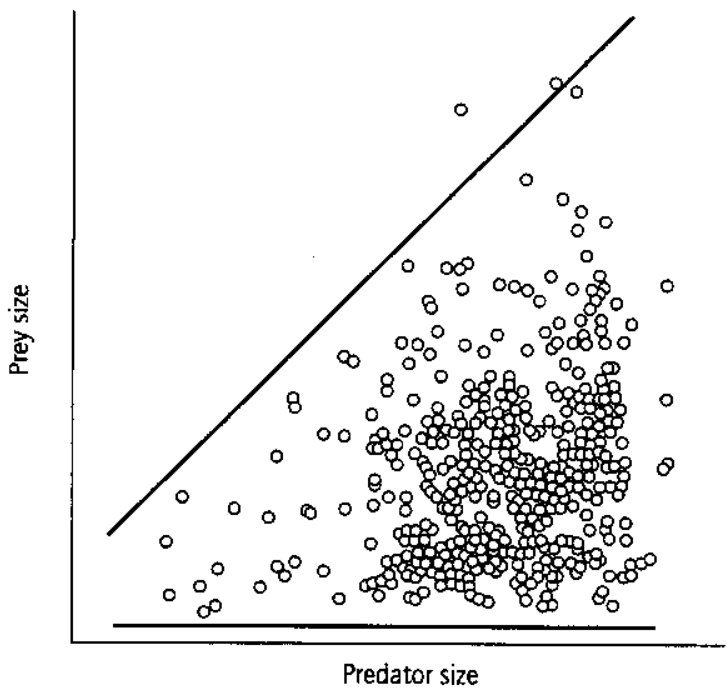

Fig. 12.3 Hypothetical predator size-prey size relationship for a piscivore, illustrating typically observed changes in minimum and maximum prey sizes consumed with increasing predator size.

change only slightly over a broad range of predator sizes (Fig. 12.3). For example, Mittelbach and Persson (1998) demonstrated increasing mean and maximum prey sizes as body size increased for 12 species of freshwater piscivores. The authors further noted that for many of the piscivores they examined, minimum prey size remained fairly constant with increasing predator body size. Scharf et al. (2000) revealed similar predator size-prey size patterns for a group of 18 marine piscivores in continental shelf waters off the Atlantic coast of the USA. Expanding prey-size ranges that retain small prey in the diet of larger piscivores means that prey sizes consumed by smaller predators can be a subset of the prey sizes consumed by larger predators, which may result in a competitive disadvantage for smaller predators (Wilson 1975 |. However, when the range of prey sizes eaten is examined as a ratio of predator size rather than on an absolute scale, ontogenetic changes are more subtle. For example, Pearre (1986) studied a large group of predators that included 43 species of larvae, juveniles and some small adult fishes in an effort to detect general trends in prey-size distri- butions eaten by fish predators of varying body sizes. Based on ratio-scale analyses, he concluded that the range of prey sizes eaten did not change significantly with increasing body size for most predators and that older larger predators should not compete with smaller ones.

Although predator size-prey size relationships for piscivorous fishes are often reported, potential mechanisms that lead to the commonly observed pattern of increasing maximum prey sizes coupled with stationary minimum prey sizes are generally lacking. Scharf et al. (2000) noted that the continued inclusion of small prey in the diets of larger predators contrasts with predictions of optimal foraging models for particulate feeders, which indicate that the largest prey available should be consumed preferentially to maximize net energetic return. The authors hypothesized that the combination of high relative abundance and high capture probability for small prey relative to large prey may lead to consistently high vulnerability to predation for small prey fishes as already discussed. Because predator handling times also increase rapidly with prey size, they suggested that the retention of small prey in the diet may reflect profitable foraging decisions by predators because search, capture and handling costs remain low.

\subsubsection{What determines maximum prey size?}

Maximum prey sizes eaten by piscivores can be limited by several factors. Of foremost importance are morphological limitations imposed by predator gape size and throat width. Most piscivorous fishes swallow prey head first after manipulating prey so that the largest body depth is positioned laterally in the mouth (Reimchen 1991). A strong relationship between prey body depth and predator gape width has been detected for several piscivorous fishes (e.g. Hambright et al. 1991). General mouth shape and structure can also affect the types and sizes of prey that can be ingested. For example, Keast and Webb (1966) demonstrated strong relationships between mouth morphology and the feeding ecology of several freshwater fishes. The effects of piscivore gape limitations on 
maximum prey sizes eaten can also impact prey populations. Persson et al. (1996) examined the potential community-level effects of predator gape limitation in a field study of predation in European lakes. Prey fishes in four lakes were exposed to two predators with different gape sizes and their populations monitored. Results indicated that prey exposed to the smaller-gaped predator reached a size refuge sooner, were more abundant and had slower growth rates due to intraspecific competition compared with prey exposed to the larger-gaped predator. The effects of piscivore gape size were also observed at lower trophic levels, indicating the potential importance of predator gape sizes on community dynamics (Persson, Chapter 15, this volume).

Other factors may restrict maximum prey sizes eaten by fish predators before morphological limitations imposed by gape size become important. The behavioural tactics used by predators to search for, encounter and attack prey can affect prey sizes consumed. For example, Gaughan and Potter (1997) compared the diets and mouth sizes of five estuarine species of larval fish and concluded that mouth width had only a small influence on prey sizes eaten and that disparate feeding patterns among larvae were likely due to behavioural differences. Behavioural capabilities of both predator and prey can also contribute considerably to the sizes of prey eaten. The ability of prey to evade predators is related to body size, with larger prey being more efficient at avoiding predator strikes. Therefore, maximum prey sizes eaten by piscivorous fishes can often be considerably smaller than gape sizes (Juanes and Conover 1995; B. Christensen 1996).

\subsection{POPULATION REGULATION}

\section{Shepherd and Cushing (1990) stated that}

there is some basis for the belief that fish populations are regulated in some way. In fact, the evidence is twofold: first, that they do not explode when subjected only to low (natural) levels of mortality: secondly, that they do not collapse at all quickly, when subjected to high levels of mortality.

One of the more well accepted mechanisms put forward to explain population regulation in fish is density-dependent mortality in larval and juvenile stages through interspecific predation or cannibalism /see Section 12.6.2, Myers, Chapter 6 , this volume; Shepherd and Pope, Chapter 8, Volume 2).

Density-dependent mortality can lead to the maintenance of population stability (Murdoch and Oaten 1975; Hassell 1978). Field studies provide evidence for density-dependent mortality in marine fishes (Myers and Cadigan 1993; Forrester 1995; Hixon and Carr 1997). Several of these investigations provide evidence that piscivorous fishes are the dominant cause of density-dependent mortality. However, identifying the mechanism that generates density-dependent predation mortality has been elusive (Bailey 1994). Potential mechanisms leading to density-dependent predation mortality as a result of predator behaviour are described in Section 12.3.2. Density-dependent prey responses can also influence mortality rates. For example, competition for food at high density may lead to reduced growth rates, with prey being vulnerable to gape-limited piscivores for longer periods.

\subsubsection{Population and community effects}

Piscivorous fishes are known to have a dramatic influence on population- and community-level dynamics (Persson, Chapter 15, this volume). The impacts of piscivores can extend down several trophic levels (Zaret and Paine 1973). In freshwater systems, the trophic cascade model describes zooplanktivore, zooplankton, and phytoplankton abundance under high and low levels of piscivore abundance (see Carpenter et al. 1985; Persson, Chapter 15, this volume; Kaiser and Jennings, Chapter 16, Volume 2). When piscivore abundance levels are high, density of zooplanktivorous fish is reduced, which leads to increased zooplankton 
(herbivore) and reduced phytoplankton abundance levels. Opposite abundance levels to those described above are observed during periods of low piscivore density. Hambright (1994) describes how the vulnerability of zooplanktivores to piscivory determines the magnitude of zooplanktivory and thus its effect on lower trophic levels. Piscivorous fish can influence the life-history strategy of their prey. Reznick et al. $\{1990)$ showed that under separate piscivore regimes (low vs. high predation), guppies (Poecilia reticulata) evolved different lifehistory parameters such as age at maturity, reproductive effort, brood size and size of offspring (Hutchings, Chapter 7, this volume).

Cannibalism is interesting because of its potential role in regulating population levels through its contribution to natural mortality; however, evidence for density-dependent cannibalism in noncaptive fishes has not been discovered (Smith and Reay 1991). Henderson and Corps (1997) found that bass (Dicentrarchus labrax) year-class strength had a 3-year periodicity, which they believed to result from cannibalism within the nursery.

Animal abundance levels are known to exhibit periodicity as a result of predator-prey or host-parasite cycles. In a predator-prey cycle, increases in predator abundance are concurrent with declines in prey population levels; subsequent periods of low prey abundance can lead to predator declines and prey release. We are aware of only one example of a predator-prey cycle for a piscivorous fish. Pacific cod (Gadus macrocephalus) and herring (Clupea harengus pallasi) populations in Hecate Strait, British Columbia have patterns of abundance that are suggestive of such a cycle (Walters et al. 1986). The lack of evidence for a piscivoreprey cycle may result from the flexible feeding behaviour of piscivores, allowing them to remain at stable population levels when one of their prey populations is at low abundance.

Piscivores can have indirect non-lethal effects on prey fishes. These include all of the behavioural responses made by prey when confronted with a piscivore. These behavioural responses can lead to differences in community structure. The dominant indirect effect on prey fishes in a northern bog in the USA after northern pike were introduced was emigration; this led to a rapid decline in prey fish abundance and a change in community structure (He and Kitchell 1990).

\subsection{METHODS OF STUDYING PREDATION IN THE FIELD}

There are several methods used to determine the effects of piscivorous fish on prey populations and communities. A direct approach is to make comparisons between treatments where piscivores are present or absent. These treatments may be natural or artificial. Modelling has been used successfully to determine the influence of predators on prey populations (Mittelbach, Chapter 11 and Persson, Chapter 15, this volume). Studies that estimate predation mortality and compare this to total prey mortality make up another group of studies. Estimates of consumption rate along with knowledge of diet composition, prey sizes and predator abundance are used to estimate predation mortality. Detailed descriptions of stomach content analysis and methods to estimate consumption rates are described by Jobling (Chapter 5 , this volume).

Tethers (usually monofilament fishing line) are used to hold prey fish in place; the fate of the prey fish allows one to assess relative predation intensity in both space and time. Danilowicz and Sale (1999) used tethering of French grunt (Haemulon flavolineatum) to determine when, over a diel cycle, predation intensity was highest. They found that the risk of being eaten was lowest during diurnal periods and highest during dusk and nocturnal periods. Age-0 rainbow trout (Salmo gairdneri) were tethered in British Columbia lakes to determine the spatial and temporal patterns of piscivory; it was concluded that the risk of predation varied greatly over both space and time (Post et al. 1998). Clearly, tethering experiments, as with other predator-prey studies, would need to conform to the animal ethics regulations of the countries and institutions involved.

Filming has been used to both identify predators and gain insight into the intensity of piscivory. 
Carr and Hixon (1995) used filming of small patch reefs to aid in identifying pelagic piscivores and for measuring their visitation rates to experimental reefs.

\subsection{IMPLICATIONS FOR CONSERVATION AND MANAGEMENT}

Fishing alters the age and size structure of populations as older and larger fish are often removed first, and eventually the fishery is supported by the small newly recruited individuals. In many ecosystems, large piscivorous species were the initial targets of fishing. After the fishing down of these populations, the fisheries shifted to smaller species at lower trophic levels (Pauly and Christensen, Chapter 10, Volume 2). Although most marine landings are of small planktivores, it is fishing and the removal of large species at high trophic levels that affects ecosystem structure and functioning, leading to 'top-down' control (Carpenter et al. 1985; Hixon and Carr 1997; (Kaiser and Jennings, Chapter 16, Volume 2). For example, on Georges Bank, the decline in groundfish stocks has led to a dramatic increase in forage fish such as herring and mackerel and a replacement of gadid and flounder species by small elasmobranchs [Fogarty and Murawski 1998). As more and more stocks become overexploited, fewer top predators will dominate oceanic food webs and both direct and indirect community effects will be prevalent. Predator removals can also be a deliberate form of fisheries management, whereby decreases in predation pressure are predicted to result. However this strategy does not always proceed as predicted (V. Christensen 1996; Kaiser and Jennings, Chapter 16 and Cowx, Chapter 17, Volume 2).

The opposite problem, with similar results, occurs when predators are deliberately or inadvertently added to ecosystems (Cowx, Chapter 17, Volume 2). The effects of piscivore introduction has been documented in temperate, boreal and tropical lakes (Zaret and Paine 1973; Mills et al. 1994; Vander Zanden et al. 1999). The most dra- matic recent example has been the introduction of the Nile perch (Lates nilotica) to Lake Victoria, the world's largest tropical lake by surface area. The main effect of the predator introduction, similar to that observed in most systems where it has occurred, has been an accelerated decline of the diverse endemic cichlid fauna of the lake and the recent extinction of at least 200 species (Seehausen et al. 1997). However, the Nile perch introduction has also resulted in a fourfold increase in fishery yield and a doubling of fishery-related employment (Pitcher and Hart 1995; Kitchell et al. 1997).

Piscivore stocking, particularly in freshwater systems, has also been used as a way to improve water quality in eutrophic lakes and reservoirs. This process, termed 'biomanipulation', works through trophic cascading and has been quite successful in improving water quality of culturally eutrophic lakes and reservoirs (Drenner and Hambright 1999), al though it can also have a variety of unexpected negative impacts.

Marine reserves have been effective in restoring and protecting many reef fishes (Polunin, Chapter 14 , Volume 2) and they appear to be a promising tool for marine ecosystem sustainability (National Research Council 1999). However, reserves, if not planned carefully enough, can have negative impacts because of potential effects of physical factors combined with increased protection of piscivorous fishes. For example, in a small reserve in Barbados, size and abundance of piscivores were greater within the reserve than on adjacent reefs, but recruitment of grunts (Haemulidae) was lower because of predation pressure and oceanographic patterns of larval supply (Tupper and Juanes 1999).

\subsection{CONCLUSIONS}

Piscivores are a diverse group of fish that show distinct behaviours and specialized morphologies. The timing of the onset of piscivory is critical to many species and may have led to adaptive strategies that accelerate the shift to piscivory. The predation process can be better understood by examining the components of predation, and the 
predatory response to changes in prey density can be estimated by generating numerical and functional responses. Piscivorous fish exhibit general patterns of prey type and size selectivity driven by attack behaviours and prey-specific behavioural responses by the prey. Predatory fish can have large impacts on prey communities in all habitats where they occur and are thus common targets for conservation and management, as they are often the first species to be affected by harvesting; however, they can also have both positive and detrimental effects when deliberately or inadvertently added to ecosystems.

\section{REFERENCES}

Adams, S.M. and DeAngelis, D.L. (1987) Indirect effects of early bass-shad interactions on predator population structure and food web dynamics. In: W.C. Kerfoot and A. Sih (eds) Predation: Direct and Indirect Impacts on Aquatic Communities. Hanover, NH: University Press of New England, pp. 103-17.

Bailey, K.M. (1994) Predation on juvenile flatfish and recruitment variability. Netherlands Journal of Sea Research 32, 175-89.

Blake, R.W. (1983) Fish Locomotion. Cambridge: Cambridge University Press.

Buckel, J.A., Letcher, B.H. and Conover, D.O.(1998) Effects of a delayed onset of piscivory on size of age-0 bluefish. Transactions of the American Fisheries Society 127, 576-87.

Buckel, J.A., Fogarty, M.J. and Conover, D.O. (1999a) Mutual prey of fish and humans: a comparison of biomass consumed by bluefish, Pomatomus saltatrix, with that harvested by fisheries. Fishery Bulletin 97, 776-85.

Buckel, J.A., Conover, D.O., Steinberg, N.D. and McKown, K.A. (1999b) Impact of age-0 bluefish predation on age- 0 fishes in the Hudson River estuary: evidence for density-dependent loss of juvenile striped bass. Canadian Journal of Fisheries and Aquatic Sciences 56, 275-87.

Buckel, J.A., Fogarty, M.J. and Conover, D.O. (1999c) Foraging habits of bluefish, Pomatomus saltatrix, on the U.S. east coast continental shelf. Fishery Bulletin 97, 758-75.

Buijse, A.D. and Houthuijzen, R.P. \{1992\} Piscivory, growth, and size-selective mortality of age 0 pikeperch (Stizostedion lucioperca). Canadian Journal of Fisheries and Aquatic Sciences 49, 894-902.
Carpenter, S.R., Kitchell, J.F. and Hodgson, J.R. (1985) Cascading trophic interactions and lake productivity. BioScience 35, 634-9.

Carr, M.H. and Hixon, M.A. (1995) Predation effects on early post-settlement survivorship of coral-reef fishes. Marine Ecology Progress Series 124, 31-42.

Chesson, J. (1978) Measuring preference in selective predation. Ecology 59, 211-15.

Christensen, B. (1996) Predator foraging capabilities and prey antipredator behaviours: pre- versus postcapture constraints on size-dependent predator-prey interac. tions. Oikos 76, 368-80.

Christensen, V. (1996) Managing fisheries involving predator and prey species. Reviews in Fish Biology and Fisheries 6, 417-42.

Danilowicz, B.S. and Sale, P.F. (1999) Relative intensity of predation on the French grunt, Haemulon flavolineatum, during diurnal, dusk, and nocturnal periods on a coral reef. Marine Biology 133, 337-43.

Dill, L.M. (1983) Adaptive flexibility in the foraging behavior of fishes. Canadian Journal of Fisheries and Aquatic Sciences 40, 398-408.

Drenner, R.W. and Hambright, K.D. (1999) Biomanipulation of fish assemblages as a lake restoration technique. Archiv für Hydrobiologie 146, 129-65.

Eby, L.A., Rudstam, L.G. and Kitchell, J.F. (1995) Predator responses to prey population dynamics: an empirical analysis based on lake trout growth rates. Canadian Journal of Fisheries and Aquatic Sciences 52, 1564-71.

Eklöv, P. (1992) Group foraging versus solitary foraging efficiency in piscivorous predators: the perch, Perca fluviatilis, and pike, Esox lucius, patterns. Animal Behaviour 44, 313-26.

Fogarty, M.J. and Murawski, S.A. (1998) Large-scale disturbance and the structure of marine systems: fishery impacts on Georges Bank. Ecological Applications $\mathbf{8}$ (Suppl.), S6-S22.

Forney, J.L. (1971)Development of dominant year classes in a yellow perch population. Transactions of the American Fisheries Society 100, 739-49.

Forrester, G.E. \{1995\} Strong density-dependent survival and recruitment regulate the abundance of a coral reef fish. Oecologia 103, 275-82.

Frankiewicz, P., Dabrowski, K. and Zalewski, M. (1996) Mechanism of establishing bimodality in a size distribution of age-0 pikeperch, Stizostedion lucioperca (L.) in the Sulejow Reservoir, central Poland. Annales Zoologie Fennici 33, 321-7.

Gaughan, D.J. and Potter, I.C. (1997) Analysis of diet and feeding strategies within an assemblage of estuarine larval fish and an objective assessment of dietary niche overlap. Fishery Bulletin 95, 722-31.

Gerking, S.D. (1994) Feeding Ecology of Fish. New York: Academic Press. 
Gerritsen, J. and Strickler, J.E. (1977) Encounter probabilities and community structure in zooplankton: a mathematical model. Journal of the Fisheries Research Board of Canada 34, 73-82.

Greene, C.H. \{1986\} Patterns of prey selection: implications of predator foraging tactics. American Naturalist 128, 824-39

Hambright, K.D. (1994) Morphological constraints in the piscivore-planktivore interaction: implications for the trophic cascade hypothesis. Limnology and Oceanography 39, 897-912.

Hambright, K.D., Drenner, R.W., McComas, S.R. and Hairston, N.G. (1991) Gape-limited piscivores, planktivore size refuges, and the trophic cascade hypothesis. Archiv für Hydrobiologie 121,389-404.

Hart, P.J.B. (1993) Teleost foraging: facts and theories. In: T.J. Pitcher (ed.) Behaviour of Teleost Fishes. London: Chapman \& Hall, pp. 253-84.

Hart, P.J.B. and Hamrin, S.F. $\{1990\}$ The role of behaviour and morphology in the selection of prey by pike. In: Hughes (ed.) Behavioural Mechanisms of Food Selection. Heidelberg: Springer-Verlag, pp. 235-54.

Hassell, M.P. (1978) The Dynamics of Arthropod Preda. tor-Prey Systems. Princeton, NJ: Princeton University Press.

He, X. and Kitchell, J.F. (1990) Direct and indirect effects of predation on a fish community: a whole lake experiment. Transactions of the American Fisheries Society 119, 825-35.

Henderson, P. and Corps, M. (1997) The role of temperature and cannibalism in interannual recruitment variation of bass in British waters. Journal of Fish Biology 50, 280-95.

Hixon, M. and Carr, M. (1997) Synergistic predation, density dependence, and population regulation in marine fish. Science 277, 946-9.

Hobson, E.S. (1991) Trophic relationships of fishes specialized to feed on zooplanters above coral reefs. In: P.F. Sale (ed.) The Ecology of Fishes on Coral Reefs. New York: Academic Press, pp. 69-95.

Holling, C.S. (1965) The functional response of predators to prey density and its role in mimicry and population regulation. Memoirs of the Entomological Society of Canado 45, 3-60.

Hoyle, J.A. and Keast, A. (1987) The effect of prey morphology and size on handling time in a piscivore, the largemouth bass (Micropterus salmoides). Canadian Journal of Zoology 65, 1972-7.

Jenkins, G.P., Milward, N.E. and Hartwick, R.F. (1984) Food of larvae of Spanish mackerels, genus Scomberomorus (Teleostei: Scombridae), in shelf waters of the Great Barrier Reef. Australian Journal of Marine and Freshwater Research 35, 477-82.

Juanes, F. (1994) What determines prey size selectivity in piscivorous fishes? In: D.J. Stouder, K.L. Fresh and R.J Feller (eds) Theory and Application in Studies of Fish Feeding Ecology. Columbia, SC: University of South Carolina Press, pp. 79-100.

Juanes, F. and Conover, D.O. (1994a) Piscivory and prey size selection by young-of-the-year bluefish: predator preference or size-dependent capture success? Marine Ecology Progress Series 114, 59-69.

Juanes, F. and Conover, D.O. (1994b) Rapid growth, high feeding rates, and early piscivory in young-of-the-year bluefish (Pomatomus saltatrix). Canadian Journal of Fisheries and A quatic Sciences 51, 1752-61.

Juanes, F. and Conover, D.O. (1995) Size-structured piscivory: advection and the linkage between predator and prey recruitment in young-of-the-year bluefish. Marine Ecology Progress Series 128, 287-304.

Juanes, F., Buckel, J.A. and Conover, D.O. (1994) Accelerating the onset of piscivory: intersection of predator and prey phenologies. Journal of Fish Biology 45 (Suppl. A), 41-54.

Keast, A. (1985) The piscivore guild of fishes in small freshwater ecosystems. Environmental Biology of Fishes 12, 119-29.

Keast, A. and Webb, D. (1966) Mouth and body form relative to feeding ecology in the fish fauna of a small lake, Lake Opinicon, Ontario. Journal of the Fisheries Research Board of Canada 23, 1845-74.

Kitchell, J.F., Schindler, D.S., Ogutu-Ohwayo, R. and Reinthal, P.M. \{1997\} The Nile perch in Lake Victoria: interactions between predation and fisheries. Ecological Applications 7, 653-64.

Magnússon, K.G. (1995) An overview of the multispecies VPA: theory and applications. Reviews in Fish Biology and Fisheries 5, 195-212.

Mangel, M. (1996) Life history invariants, age at maturity and the ferox trout. Evolutionary Ecology 10, 249-63.

Margulies, D. (1997) Development of the visual system and inferred performance capabilities of larval and early juvenile scombrids. Marine Behaviour and Physiology $30,75-98$.

Mathias, J.A. and Li, S. \{1982\} Feeding habits of walleye larvae and juveniles: comparative laboratory and field studies. Transactions of the American Fisheries Society 111, 722-35.

Miller, T.J., Crowder, L.B., Rice, J.A. and Marschall, E.A. (1988) Larval size and recruitment mechanisms in fishes: toward a conceptual framework. Canadian Journal of Fisheries and Aquatic Sciences 45, 1657-70.

Mills, E.L., Leach, J.H., Carlton, J.T. and Secor, C.L. (1994) Exotic species and the integrity of the Great Lakes. Bioscience 44, 666 76.

Mittelbach, G.G. and Persson, L. (1998) The ontogeny of piscivory and its ecological consequences. Canadian Journal of Fisheries and Aquatic Sciences 55, 1454-65. 
Murdoch, W.W. and Oaten, A. (1975) Predation and population stability. Advances in Ecological Research 9, 1-131.

Myers, R.A. and Cadigan, N.G. (1993) Densitydependent juvenile mortality in marine demersal fish. Canadian Journal of Fisheries and Aquatic Sciences 50, 1576-90.

National Research Council (1999) Sustaining Marine Fisheries. Washington, DC: National Academy Press.

Olson, M.H. (1996) Ontogenetic shifts in largemouth bass: variability and consequences for first-year growth. Ecology 77, 179-90.

Pearre, S. (1986) Ratio-based trophic niche breadths of fish, the Sheldon spectrum, and the size-efficiency hypothesis. Marine Ecology Progress Series 27, 299314.

Persson, L., Andersson, J., Wahlstrom, E. and Eklov, P. (1996) Size-specific interactions in lake systems: predator gape limitation and prey growth rate and mortality. Ecology 77, 900-11.

Peterman, R.M. and Gatto, M. (1978) Estimation of functional responses of predators on juvenile salmon. Journal of the Fisheries Research Board of Canada 35, 797-808.

Petersen, J.H. and DeAngelis, D.L. (1992) Functional response and capture timing in an individual-based model: predation by northern squawfish (Pty. chocheilus oregonensis) on juvenile salmonids in the Columbia River. Canadian Journal of Fisheries and Aquatic Sciences 49, 2551-65.

Pitcher, T.J. and Hart, P.J.B. (1995) The Impacts of Species Changes in African Lakes. London: Chapman \& Hall.

Pitcher, T.J. and Parrish, J.K. (1993) Functions of shoaling behaviour in teleosts. In: T.J. Pitcher (ed.) The Behaviour of Teleost Fishes. London: Chapman \& Hall, pp. 363-439.

Post, J.R., Parkinson, E.A. and Johnston, N.T. (1998) Spatial and temporal variation in risk to piscivory of age- 0 rainbow trout: patterns and population level consequences. Transactions of the American Fisheries Society 127, 932-42.

Reimchen, T.E. (1991) Evolutionary attributes of headfirst prey manipulation and swallowing in piscivores. Canadian Journal of Zoology 69, 2912-16.

Reznick, D.A., Bryga, H. and Endler, J.A. (1990) Experimentally induced life-history evolution in a natural population. Nature 346, 357-9.

Rice, J.A., Crowder, L.B. and Rose, K.A. (1993) Interactions between size-structured predator and prey populations: experimental test and model comparison. Transactions of the American Fisheries Society 122, 481-91.

Ruggerone, G.T. and Rogers, D.E. (1983) Arctic charr pre- dation on sockeye salmon smolts at Little Togiak River, Alaska. Fishery Bulletin 82, 401-10.

Sazima, I. (1998) Field evidence for suspension feeding in Pseudocaranx dentex, with comments on ram filtering in other jacks (Carangidae). Environmental Biology of Fishes 53, 225-9.

Scharf, F.S., Buckel, J.A., Juanes, F. and Conover, D.O. (1997) Estimating piscine prey size from partial remains: testing for shifts in foraging mode by juvenile bluefish. Environmental Biology of Fishes 49, 377-88. Scharf, F.S., Buckel, J.A., Juanes, F. and Conover, D.O (1998) Predation by juvenile piscivorous bluefish (Pomatomus saltatrix): the influence of prey to predator size ratio and prey type on predator capture success and prey profitability. Canadian Journal of Fisheries and Aquatic Sciences 55, 1695-703.

Scharf, F.S., Juanes, F. and Rountree, R.A. (2000) Predator size-prey size relationships of marine fish predators: interspecific variation and the effects of ontogeny and body size on trophic niche breadth. Marine Ecology Progress Series 208, 229-48.

Seehausen, O., Witte, F., Katunzi, E.F., Smits, J. and Bouton, N. (1997) Patterns of remnant cichlid fauna in southern Lake Victoria. Conservation Biology 11, 890-904.

Shepherd, J.G. and Cushing, D.H. (1990) Regulation in fish populations: myth or mirage? Philosophical Transactions of the Royal Society of London Series $B$ 330, 151-64.

Sih, A. and Christensen, B. (2001) Optimal diet theory: when does it work and when and why does it fail? Animal Behaviour 61,379-90.

Skulason, S., Snorrason, S.S., Ota, D. and Noakes, D.L.G. (1993) Genetically based differences in foraging behaviour among sympatric morphs of arctic charr (Pisces: Salmonidael. Animal Behaviour 45, 1179-92.

Smith, C. and Reay, P. (1991) Cannibalism in teleost fish. Reviews in Fish Biology and Fisheries 1, 41-64.

Sogard, S.M. (1997) Size-selective mortality in the juvenile stage of teleost fishes: a review. Bulletin of Marine Science 60, 1129-57.

Stephens, D.W. and Krebs, J.R. (1986) Foraging Theory. Princeton, NJ: Princeton University Press.

Tanaka, M., Kaji, T., Nakamura, Y. and Takahashi, Y. (1996) Developmental strategies of scombrid larvae: high growth potential related to food habits and precocious digestive system development. In: Y. Watanabe Y. Yamashita and Y. Oozeki (eds) Survival Strategies in Early Life Stages of Marine Resources. Rotterdam: A.A. Balkema, pp. 125-39.

Tupper, M. and Juanes, F. (1999) Effects of a marine reserve on recruitment of grunts (Pisces: Haemulidae) at Barbados, West Indies. Environmental Biology of Fishes 55, 53-63. 
Utne-PaIm, A.C. (2000) Prey visibility, activity, size and catchability's (evasiveness) influence on Gobiusculus flavescens prey choice. Sarsia 85, 157-65.

Vander Zanden, M.J., Casselman, J.M. and Rasmussen, J.B. [1999) Stable isotope evidence for the food web consequences of species invasions in lakes. Nature 401, 464-7.

Wahl, D.H. and Stein, R.A. (1988) Selective predation by three esocids: the role of prey behavior and morphology. Transactions of the American Fisheries Society $117,142-51$.

Wainwright, P.C. and Rich ard, B.A.\{1995\} Predicting patterns of prey use from morphology of fishes. Environmental Biology of Fishes 44, 97-113.

Walters, C.J., Stocker, M., Tyler, A.V. and Westrheim, S.J. \{1986\} Interaction between Pacific cod (Gadus macrocephalus) and herring (Clupea harengus pallasi) in the Hecate Strait, British Columbia. Canadian Journal of Fisheries and Aquatic Sciences 43, 830-7.

Webb, P.W. (1976) The effect of size on the fast-start performance of rainbow trout, Salmo gairdneri, and a consideration of piscivorous predator-prey interactions. Journal of Experimental Biology 65, 157-77.
Werner, E.E. (1977) Species packing and niche complementarity in three sunfishes. American Naturalist $111,553-78$.

Werner, E.E. and Gilliam, J.F. (1984) The ontogenetic niche and species interactions in size-structured populations. Annual Review of Ecology and Systematics 15, 393-425.

Wilson, D.S. (1975) The adequacy of body size as a niche difference. American Naturalist 109, 769-84.

Winemiller, K.O. (1989) Ontogenetic diet shifts and resource partitioning among piscivorous fishes in the Venezuelan Llanos. Environmental Biology of Fishes 26, 177-99.

Wootton, R.J. (1990) Ecology of Teleost Fishes. New York: Chapman \& Hall.

Wright, R.A., Crowder, L.B. and Martin, T.H. (1993) The effects of predation on the survival and size. distribution of estuarine fishes: an experimental approach. Environmental Biology of Fishes 36, 291300.

Zaret, T.M. and Paine, R.T. (1973) Species introduction in a tropical lake. Science 182, 449-55. 


\title{
Handbook of Fish Biology and Fisheries
}

\section{VOLUME 1 \\ FISH BIOLOGY}

\author{
EDITED BY \\ Paul J.B. Hart \\ Department of Biology \\ University of Leicester \\ AND \\ John D. Reynolds \\ School of Biological Sciences \\ University of East Anglia
}


(C) 2002 by Blackwell Science Ltd a Blackwell Publishing company

Chapter $8 \stackrel{\circ}{ }$ British Crown copyright, 1999

350 Main Street, Malden, MA 02148-5018, USA

108 Cowley Road, Oxford OX4 1JF, UK

550 Swanston Street, Carlton South, Melbourne, Victoria 3053, Australia

Kurfürstendamm 57, 10707 Berlin, Germany

The right of Paul J.B. Hart and John D. Reynolds to be identified as the Authors of the Editorial Material in this Work has been asserted in accordance with the UK Copyright, Designs, and Patents Act 1988.

All rights reserved. No part of this publication may be reproduced, stored in a retrieval system, or transmitted, in any form or by any means, electronic, mechanical, photocopying, recording or otherwise, except as permitted by the UK Copyright, Designs, and Patents Act 1988, without the prior permission of the publisher.

First published 2002 by Blackwell Science Ltd

Library of Congress Cataloging-in-Publication Data has been applied for.

Volume 1 ISBN 0-632-05412-3 (hbk)

Volume 2 ISBN 0-632-06482-X (hbk)

2-volume set ISBN 0-632-06483-8

A catalogue record for this title is available from the British Library.

Set in 9/11.5 pt Trump Mediaeval

by SNP Best-set Typesetter Ltd, Hong Kong

Printed and bound in the United Kingdom by TJ International Ltd, Padstow, Cornwall.

For further information on

Blackwell Publishing, visit our website:

http://www.blackwellpublishing.com 